\title{
La parte y el todo. Latinoamérica en la imaginación de Alfonso Reyes y Xul Solar
}

\section{The Part and the Whole. Latin America in the Imagination of Alfonso Reyes and Xul Solar}

\author{
SABRINA GiL \\ CONICET-CELEHIS / Universidad Nacional de Mar del Plata \\ sgilmdp@gmail.com
}

\begin{abstract}
RESUMEN: Este ensayo analiza las relaciones entre Alfonso Reyes y el artista argentino Xul Solar en torno a un proyecto resonante: la independencia cultural americana desde la integración de lo local y lo universal. Proponemos el trazado de líneas imaginarias entre Visión de Anáhuac y una selección de acuarelas de Solar con foco en la actualización del pasado americano perimido por la Conquista y la Colonización y la resignificación de herramientas culturales provenientes de la tradición occidental. Esperamos establecer una matriz común, donde la interrogación sobre el presente y la búsqueda de un arte y una literatura autónomos propician la imaginación del pasado prehispánico mediante experimentaciones formales, en alguna medida, equivalentes en la escritura y la pintura.
\end{abstract}

\author{
Palabras Clave: \\ Alfonso Reyes; \\ Xul Solar; \\ Latinoamérica; \\ pasado prehispánico; \\ utopía; \\ vanguardias.
}

KEYWORDS:

Alfonso Reyes;

Xul Solar;

Latin America;

Pre-Hispanic past;

Utopia;

Avant-garde.
ABSTRACT: This essay analyzes the relations between Alfonso Reyes and Argentinean artist Xul Solar about an evocative project: an American cultural independence from the integration of the local and universal. We propose tracing imaginary lines between Visión de Anáhuac and a selection of Solar's watercolors to focus on the updating of the American past that has been superseded by the Conquest and Colonization and the resignification of cultural tools derived from the Western tradition. Our aim is to establish a common matrix, where the interrogation of the present and the search for an autonomous art and literature 
favor the imagination of the pre-Hispanic past through formal experimentations, to some extent, equivalent in writing and painting.

recepción: 24 septiembre 2018 aceptación: 12 marzo 2019

Un mexicano y un argentino en dos puntos diferentes de una Europa azotada por la primera guerra y la posguerra imaginan América y la afirman desde la distancia. Alfonso Reyes escribe Visión de Anáhuac 1519 ([1915] 2006) y Xul Solar empieza a trabajar en su neocriollo para la unidad latinoamericana mientras pinta una extensa serie de imágenes que recuperan y actualizan imaginarios precolombinos, como Nana Watzin, Tlaloc, Chaco, Piai, Cuatro cholas (todas de 1923). Desplazados físicamente del presente de sus países, se internan en el conocimiento de su pasado profundo y despliegan en el terreno del arte la configuración de un futuro deseado, que es también un presente anhelado y una memoria imaginada. Sumergidos en el seno de la cultura occidental, Reyes revisa los manuscritos mexicanos de la Biblioteca Nacional de Madrid y estudia las crónicas de la conquista (Colombi 2004; Rovira Collado 2004), y Xul visita muestras de arte precolombino acopiando catálogos y volúmenes sobre arte mesoamericano y andino (Artundo 2005; Fischler 2009). ${ }^{1}$ La experiencia europea, lejos de distanciarlos de América les provee un repertorio de imágenes, fórmulas, arcaísmos, estilos, mitos... dimensiones del pasado americano perimido por la Conquista que ambos, sin conocerse, refractan en un proyecto resonante: la independencia cultural americana desde la integración de lo local y lo universal.

1 En su visita al museo de Londres adquiere $A$ short guide to the American antiquities on the British Museum (1912) y Handbook to the ethnographical collections (1910). Allí también compra Vision and design (1920) de Roger Fry, que incluye el famoso ensayo "Arte antiguo americano". El trabajo inédito de Viviana Fischler sobre los libros que adquirió en Alemania y llevó consigo en su regreso a Buenos Aires revela una importante presencia de material sobre América precolombina. Entre ellos destacan Mexikanische Kunst (1922) de la serie Orbis Pictus, escrito por Walter Lehmann (traductor de textos nahuas al alemán), señalado como el primer volumen centrado exclusivamente en arte mexicano antiguo y los tres tomos de Th. W. Danzel sobre México (1922). 
Este ensayo propone el trazado de líneas imaginarias entre textos ${ }^{2}$ de Reyes y de Xul Solar en torno a un nudo problemático de envergadura en la producción cultural latinoamericana de las primeras décadas del siglo xx: las vías de construcción de un arte y una literatura autónomos. A partir de la identificación de vasos comunicantes entre ambos, la propuesta aspira tanto a una profundización de la inserción de Xul en una trama discursiva de orientación latinoamericanista como a promover nuevas lecturas de un texto fundante y ampliamente visitado por la crítica como es Visión de Anáhuac. Vale anotar, a modo de justificación, que entre las producciones y las trayectorias sociales de Xul y de Reyes en las primeras décadas del siglo Xx encontramos múltiples conexiones que fundamentan esta lectura relacional, entre ellas: la experiencia del viaje intelectual (Colombi 2004) y las cartas de ciudadanía universal que esto les provee, perspectivas coincidentes con respecto al derecho de escritores y artistas latinoamericanos a portar la cultura europea en una integración original y no subordinada (y en esta línea, la construcción de metáforas equivalentes, como la mayoría de edad de las naciones americanas), o la exploración de formas artísticas que desbordan fronteras, ya de géneros, ya de lenguajes y, especialmente, de tiempos Nos importa rescatar lo que consideramos una matriz común, donde la interrogación sobre el presente y la búsqueda de independencia cultural propician la imaginación del pasado prehispánico mediante experimentaciones formales en alguna medida equivalentes en la escritura y la pintura.

Sin embargo, antes de introducirnos en consideraciones más estrictas nos permitimos una suerte de experimento ficcional cuya utilidad heurística residiría en establecer un paralelismo entre Visión de Anáhuac y las acuarelas de Xul, una lectura diversa de la inherente a un análisis convencional. La primera parte de Visión de Anáhuac, signada por el epígrafe de Von Humboldt: "Viajero: has Ilegado a la región más transparente del aire" (Reyes 2006: 27), convoca a una visión de las estampas de Giovanni Battista Ra-

2 Usamos texto en sentido barthesiano como "formas que significan" (Barthes 1990: 118), cuya función, "ya no es sólo comunicar o expresar, sino imponer un más allá del lenguaje que es, a la vez, la Historia y la posición que se toma frente a ella" (Barthes 2011: 11). Este uso remite a la noción de tejido y nos posibilita atender y poner en relación modulaciones verbales y pictóricas. 
musio. ${ }^{3}$ Proponemos desde aquí un ejercicio de imaginación: suplantar las imágenes de Ramusio por las de Xul, como si sus acuarelas conformasen el volumen Delle navigationi et viaggi, a través del cual Reyes introduce al lector en la descripción de Anáhuac. Imaginemos así, que la solicitud "Deténganse aquí nuestros ojos" (2006: 28) nos pide observar un conjunto de acuarelas y que "las estampas, finas y candorosas" (28) no son otras que las imágenes que conforman la utopía latinoamericana de Xul.

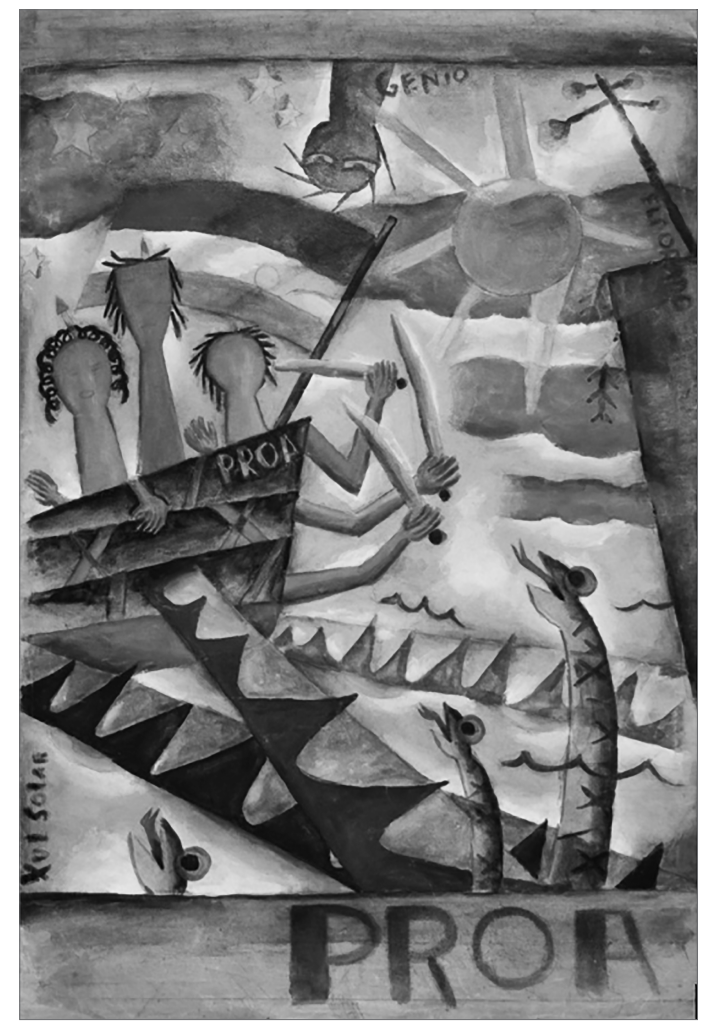

1. Xul Solar, Proa, 1925

3 Sobre la actualización y recuperación de la compilación de Ramusio en Visión de Anáhuac véase el trabajo de Rovira Collado, quien afirma que constituye su fuente principal y marca la línea principal del texto, dado que Reyes no sólo toma de allí apoyos visuales y verbales, sino que se plantea el mismo objetivo que Ramusio: proponer "una imagen de las tierras americanas cargada de lirismo" y "acercar esa imagen a Europa" (202), tarea que no se proponen Cortés ni Díaz del Castillo (fuentes igualmente presentes), concentrados en relatar sus experiencias como conquistadores. 
La recopilación de este álbum imaginario podría comenzar con la acuarela América (1923) donde "se aprecia la progresiva conquista de los litorales" (Reyes 2006: 27), o bien con Proa (1925), cuyas embarcaciones "se deslizan por una raya que cruza el mar; en pleno océano, se retuerce, como cuerno de cazador, un monstruo marino, y en el ángulo irradia picos una fabulosa estrella náutica" (27). Esta acuarela-estampa podría haber traído las "noticias extraordinarias y amenas narraciones geográficas" (27), donde "hombres y fieras de otros climas" (28) tripulan una embarcación de cuyas tablas emergen brazos con espadas, el océano embravecido la sacude y atraviesa en bandas diagonales y serpientes marinas la amenazan con lenguas extendidas y pupilas dilatadas.

Para introducir al lector-viajero en "la región más transparente del aire" (27), Reyes podría haber partido de la observación de Ña Diáfana (1923), del sonido latino de la ñ y de su doble carácter translúcido en el nombre y en la imagen: un entorno árido y luminoso, dominado por un cuerpo de límites ambiguos, pues su interior y su exterior parecen una y la misma cosa. El bastón en forma de serpiente, la dualidad de la luna y el sol y el atavío de la figura antropomórfica proponen una ubicación témporoespacial en el mundo náhuatl; por ello, Reyes podría haber encontrado en Ña Diáfana, "la visión más propia de nuestra naturaleza" (33):

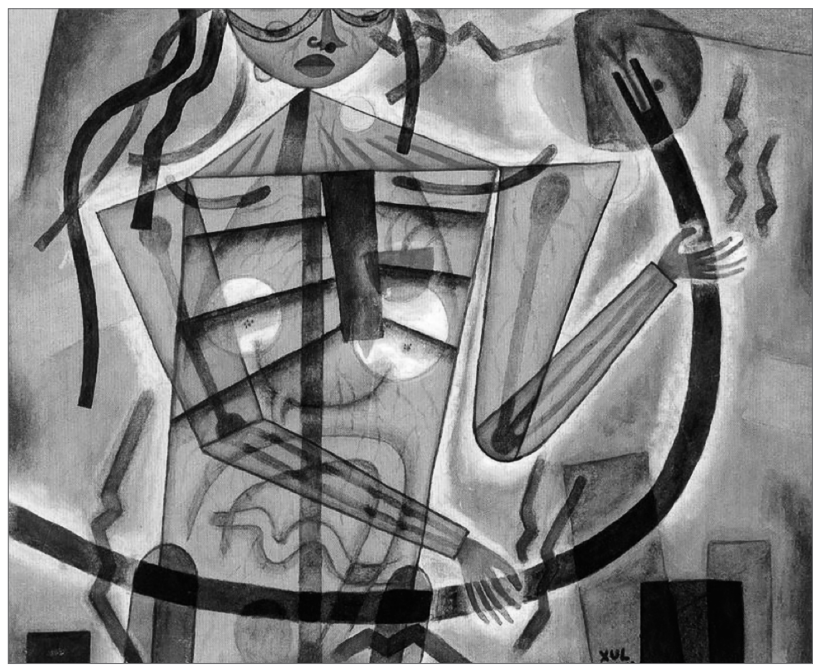

2. Xul Solar, Ña Diáfana, 1923 
Allí la vegetación arisca y heráldica, el paisaje organizado, la atmósfera de extrema nitidez, en que los colores mismos se ahogan — compensándolo la armonía general del dibujo, el éter luminoso en que se adelantan las cosas con un resalte individual; $y$, en fin, para de una vez decirlo en las palabras del modesto y sensible fray Manuel de Navarrete:

una luz resplandeciente que hace brillar la cara de los cielos (Reyes 2006: 33).

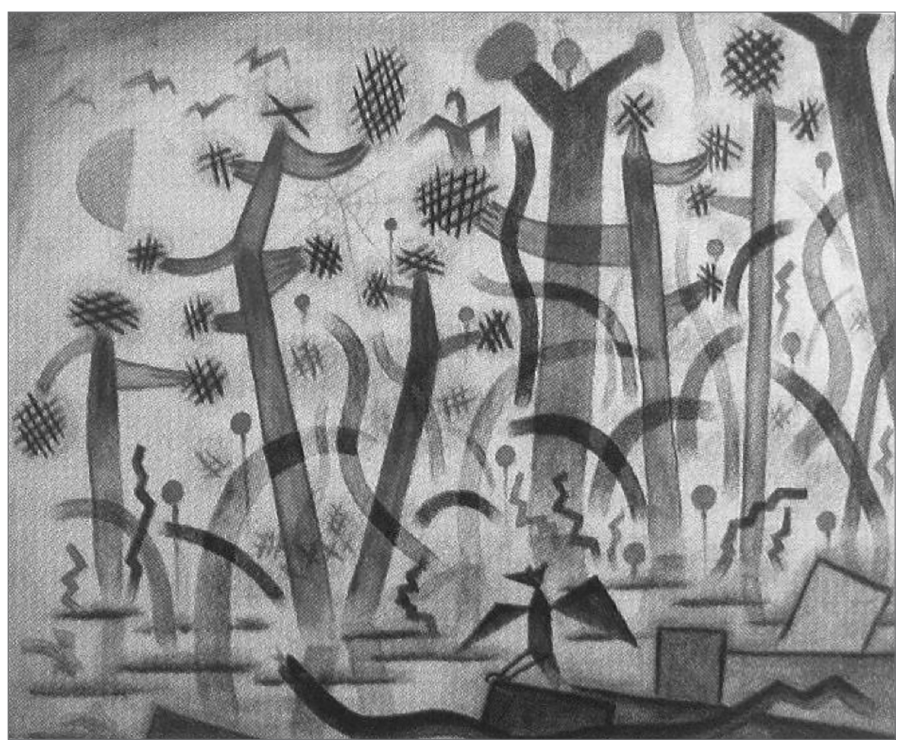

3. Xul Solar, Serpientes y cintas, 1925

Para describir las regiones exuberantes del valle, Reyes pudo haber observado en Serpientes y cintas (1925) la vastedad de plantas, frutos, nopales "-semejanza del candelabro_- conjugados en una superposición necesaria, grata a los ojos: todo ello nos aparece como una flora emblemática, y todo como concebido para blasonar un escudo" (Reyes 2006: 29; destacado nuestro). En la imagen de Xul, bajo la vegetación con ramas como candelabros, alzada en planos superpuestos, un ave (puede ser un águila) se posa sobre una serpiente en un lago, visión mítica de la fundación de Tenochtitlan y símbolo del escudo nacional mexicano, al que refiere Reyes. Entre las estampas pudo haber encontrado también la acuarela Tlaloc (1923), en la que el dios de la Iluvia, extático, pasea su mirada espiritual: 


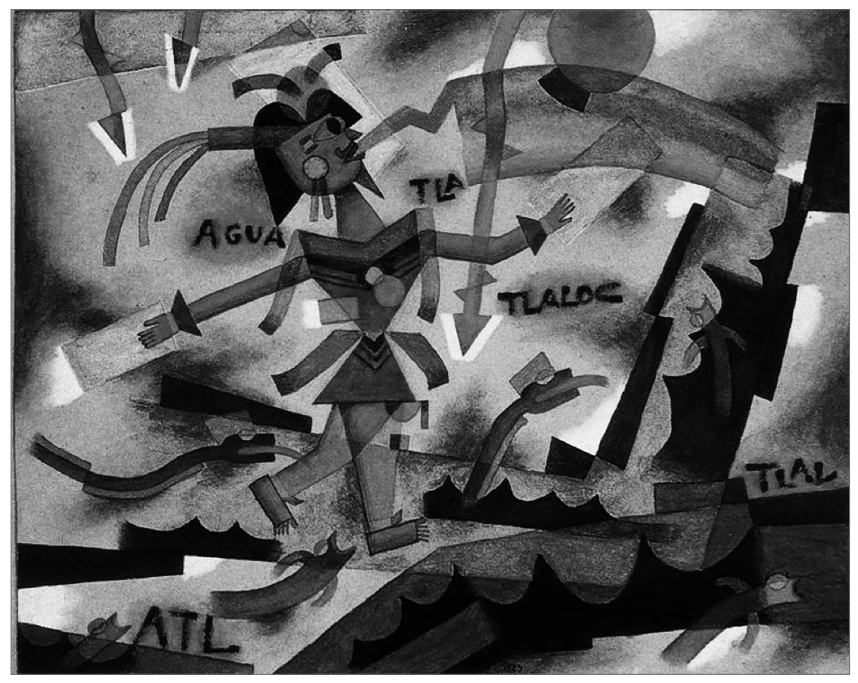

4. Xul Solar, Tlaloc, 1923

En aquel paisaje, no desprovisto de cierta aristocrática esterilidad por donde los ojos yerran con discernimiento, la mente descifra cada línea y acaricia cada ondulación; bajo aquel fulgurar del aire y en su general frescura y palidez, pasearon aquellos hombres ignotos la amplia y meditabunda mirada espiritual. Extáticos ante aquel nopal del águila y de la serpiente — compendio feliz de nuestro campo- oyeron la voz del ave agorera que les prometía seguro asilo sobre aquellos lagos hospitalarios (Reyes 2006: 33).

En el personaje central de Tlaloc, como en Drago, Nana Watzin, Na Diáfana y muchas otras, Reyes podría haber observado las características de los antiguos nahuas:

Van y vienen las túnicas de algodón rojas, doradas, recamadas, negras y blancas, con ruedas de plumas superpuestas o figuras pintadas. Las caras morenas tienen una impavidez sonriente, todas en el gesto de agradar. Tiemblan en las orejas o la nariz las arracadas pesadas, y en las gargantas los collares de ocho hilos, piedras de colores, cascabeles y pinjantes de oro. Sobre los cabellos, negros y lacios, se mecen las plumas al andar (Reyes 2006: 36).

Asimismo, en las láminas de este álbum imaginario Reyes podría haber identificado inscripciones que recuerdan marcas de la fonética mesoame- 
ricana (atl, tla, Tlaloc, Nana Watzin, Tlazoltéotl, Xotolt, Chaco, Bau Chaco) y es fácil imaginar con él una conversación entre los personajes de las acuarelas como "una canturía gustosa, [con] esas xes, esas tlés, esas chés que tanto nos alarman escritas" (Reyes 2006: 36). Las similitudes son tan vastas y variadas que se podría elaborar un álbum completo de acuarelas de Xul, "de tres volúmenes in-folio" (27) como el de Ramusio, que ilustre las palabras de Reyes y que participe en su ensayo como un profuso corpus de fuentes visuales. Por nombrar algunas más: en Mundo (1925), Reyes podría haber visto "la pintoresca ciudad, emanada toda ella del templo" (37) y el ingreso al palacio de Moctezuma de "hasta seiscientos caballeros, cuyos servidores y cortejo llenan dos o tres dilatados patios y todavía hormiguean por la calle" (45). En Bau (1926), los edificios de culto que describe profusamente con sus torres cargadas "de imaginería, zaquizamíes y maderamiento picado de figuras y monstruos" (37). En Piai (1923) o en Por su cruz jura (1923) hubiera visto cómo "se retuerce el bastón en forma de culebra con dientes y ojos de nácar" (37). En Danza (1925) y en las tres variantes de San Danza (1925), vería cómo "los danzantes van apareciendo con ricos mantos, abanicos, ramilletes de rosas, papahígos de plumas que fingen cabezas de águilas, tigres y caimanes" (46).

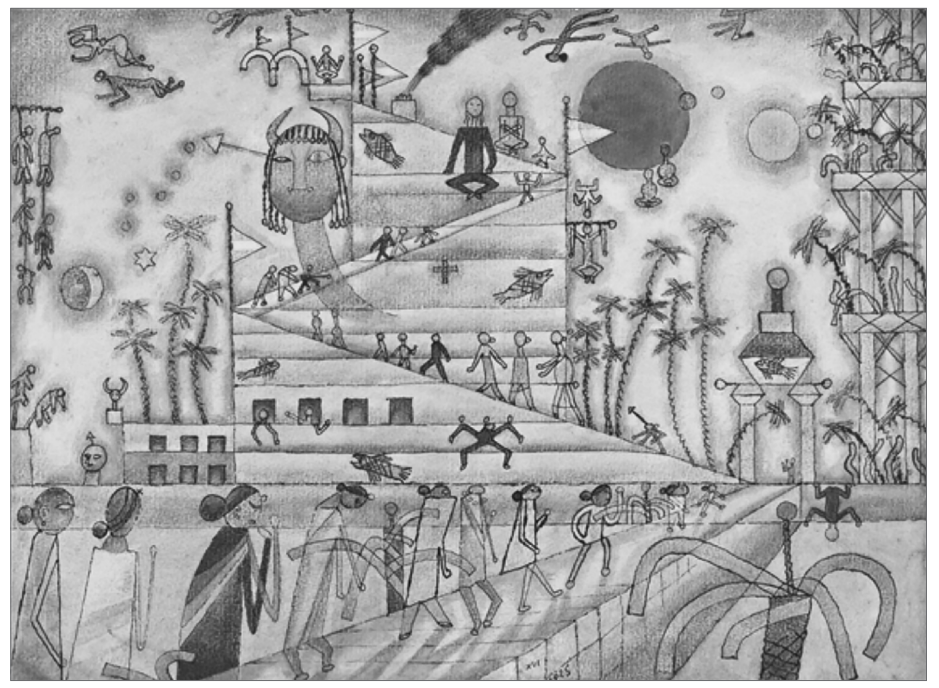

5. Xul Solar, Mundo, 1925 


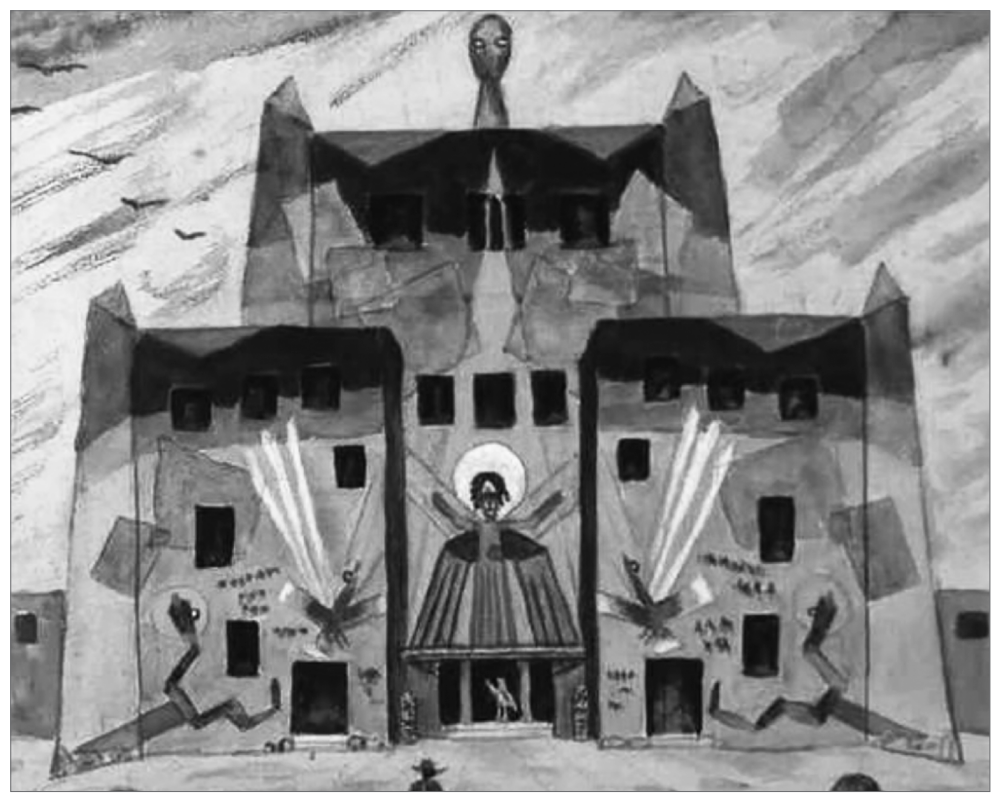

6. Xul Solar, Bau, 1926

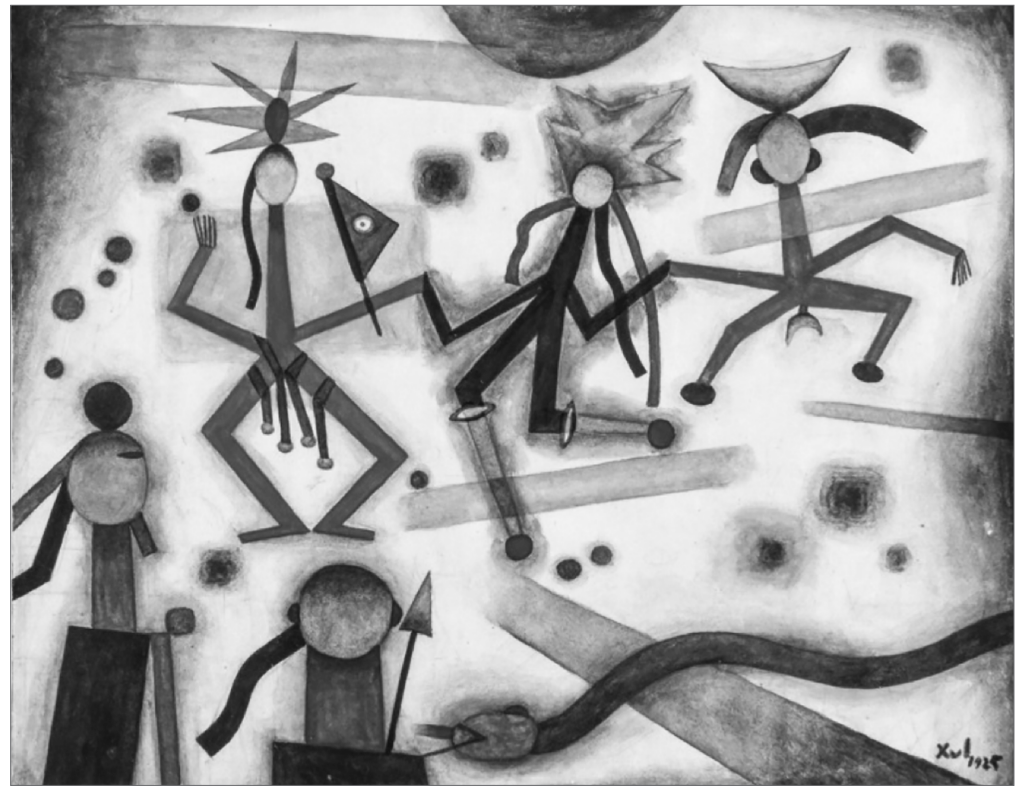

7. Xul Solar, Danza, 1925 
El experimento ficcional propuesto permite recuperar un profundo paralelismo entre textos de Xul y Reyes, centrado en la imaginación del mundo prehispánico, desde una circulación de sentidos y registros, donde la palabra escrita, el peso de la oralidad y del sonido parten de la visión y confluyen en ella. En este sentido, Yvette Jiménez de Báez afirma que en Visión de Anáhuac rigen trabajos teóricos de Reyes sobre la omisión, principio por el cual el primer plano discursivo niega el sustento del texto; así, la apelación al mundo náhuatl resulta una contracara del presente (1989: 468). En esta línea, señala que la visión es entendida en forma equivalente a un principio prehispánico de "cerrar los ojos para ver en profundidad el sentido de las cosas" (468), coincidente también con la práctica visionaria a la que Xul se dedica a lo largo de su vida. ${ }^{4}$ Pensamos que allí reside un aspecto de la familiaridad en la imaginación del pasado en Xul y Reyes, así como la preponderancia otorgada a la visión y la visualidad, medios que podrían hacer emerger lo oculto, perimido y negado en la realidad presente y en la tradición dominante.

Según Jiménez de Báez, "lo imaginado, el discurso de la utopía, revelará así, por contraste, el discurso de la Historia. En Visión de Anáhuac, será el mundo prehispánico descrito por las crónicas y cartas, es decir, el espacio tenso y contradictorio de la utopía ante el mundo de la conquista, ajustado y transformado por la visión del mundo y la actitud del autor ante los hechos del presente de la enunciación" (469). En el mismo sentido, Rovira Collado (2004) afirma que la recuperación que realiza Reyes de las compilaciones y descripciones de Ramusio, junto con su experiencia en el Centro de Estudios Históricos de Madrid, son componentes centrales de un programa cultural de recuperaciones dispuesto a responder preguntas de su presente en torno al ser y la naturaleza de la patria, eje de la última sección del texto.

Magdalena Perkowska Álvarez analiza el carácter persuasivo de la elaboración poética del pasado en Visión de Anáhuac basada en el mismo

\footnotetext{
4 Las "visiones" de Xul forman parte de una práctica de meditación orientada por hexagramas del I Ching, tendiente a propiciar el ascenso espiritual hacia un plano divino donde es posible alcanzar revelaciones extáticas. Desde 1924, y hasta su muerte, Xul registra sus visiones por escrito, en su gran mayoría en neocriollo y mediante imágenes (Artundo 2017).
} 
precepto de que Reyes parte de un proyecto de nación y responde al presente de la producción del texto. Por ello, afirma que la metátesis entre el año de escritura, 1915, y la fecha incluida en el título, 1519, sugiere que el ensayo no sólo es "una imagen poética de la historia remota de México" (2001: 86), sino una manera de leer aquel pasado en relación con el presente. Desde esta perspectiva, vale señalar que Reyes enlaza dos momentos atravesados por una circunstancia común: la inminencia del cambio, ya en el marco de la Conquista, ya en la Revolución mexicana. 1519 remite al desembarco de Cortés en Veracruz, es el grado cero de la Conquista de la región y el inicio de la transformación de la Anáhuac descrita. Jiménez de Báez señala también que para un lector erudito, 1519 refiere a la segunda carta de relación de Cortés, escrita un año después, que relata su encuentro con Moctezuma y describe Tenochtitlan en 1519. De modo significativo, la carta expone el inicio de un nuevo ciclo histórico, pues el conquistador solicita que esas tierras sean denominadas Nueva España (1989: 467).

En 1915, contexto de producción del ensayo, México está alumbrando una nueva sociedad; necesita redefinirse y volver a forjar un principio de identidad; desde ese marco Reyes actualiza la transformación originaria de Anáhuac en Nueva España y superpone los dos momentos en la escritura del ensayo, de modo que la imaginación del pasado se involucra en el esclarecimiento del presente y del futuro. En forma equivalente, las acuarelas de Xul (Nana Watzin, Drago, Tlaloc, por ejemplo) articulan elementos del pasado prehispánico y de la transculturación inicial manifiesta en los códices del comienzo de la Colonia (cfr. Armando y Fantoni 1995 y 1997), así como en mapas y estampas, para interrogar el presente y proyectar un futuro de unidad e independencia cultural deseados.

La superposición (o contención mutua) de pasado y presente en Visión de Anáhuac recuerda el efecto visual de la acuarela América, donde el instante del primer contacto Europa-América es punto de convergencia entre los mundos que eran y los que estaban a punto de empezar a ser, incluyendo sus efectos en el presente. El viejo y el nuevo continente parecen capturados en la inminencia de un contacto que podría concretarse un instante después o permanecer suspendido: las figuras antropomórficas, separadas aún por un segmento ocre de cielo/luz/mar, se buscan con los 
brazos como para tomarse entre sí, pero no tienen manos para hacerlo. Con palabras de Borges podríamos pensar que se colocan en "la inminencia de una revelación, que no se produce" (2011:12).

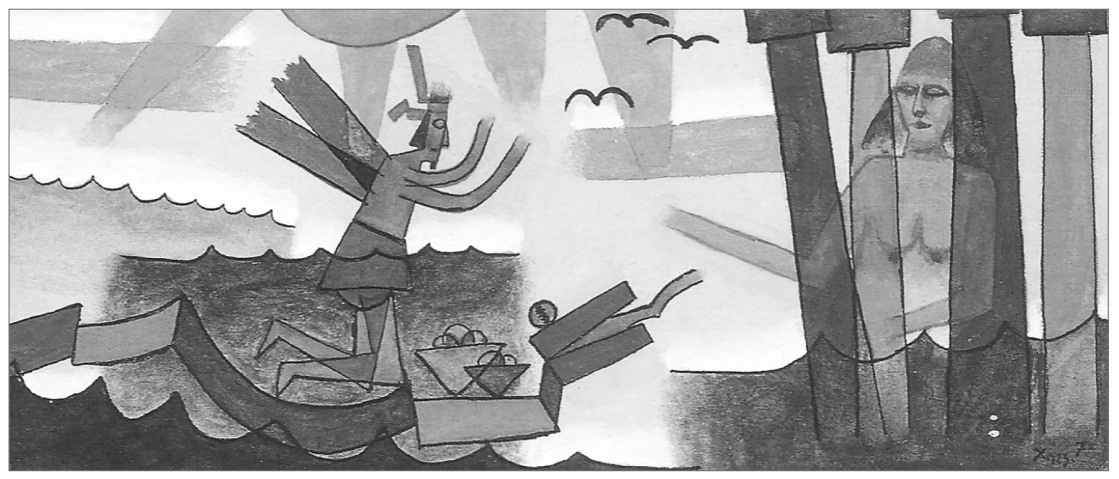

8. Xul Solar, América, 1923

La acuarela vuelve nuestra mirada hacia el pasado, hacia un escenario fundacional de la dominación europea, pero también a sus efectos posteriores, pues el personaje americano yace de rodillas, con el torso inclinado en señal de reverencia y ojos que no ven lo que se halla enfrente. En su navesierpe ${ }^{5}$ carga dos canastitos de ofrendas que le serán quitados. Asimismo, en el sector de la imagen que asociamos con Europa (derecha, según códigos cartográficos), destacan bandas anaranjadas que producen lecturas ambiguas, en tanto pueden ser columnas — de un templo y de la tradición clásica mediterránea- o barrotes; es decir, elementos que sostienen y protegen a la vez que encierran y oprimen. Por ello, parece que el brazo extendido de Europa hacia América constituye una invitación ambigua dirigida a la figura reverente, una convocatoria múltiple: a reconocer a la madre patria o madre tierra (ya que emerge de la tierra), integrarse a la tradición europea y aceptar la dominación que supone el encierro.

A su vez, la imagen de Xul actualiza la mirada sobre el pasado al enfrentar el lenguaje plástico del realismo europeo con el de las vanguardias del siglo xx, de modo que — como Reyes — introduce también una vincu-

5 Tomamos el término de la acuarela Fluctúa navesierpe (1922) que presenta una figura ambivalente y aglutinada que es, en simultáneo, una serpiente articulada y una embarcación. 
lación entre transformaciones sociales y artísticas. La figura que evoca a América contiene marcas semánticas propias de la representación estereotipada de los indios (vincha con plumas, taparrabos, piel cobriza, cabello oscuro y largo), pero su trazado pictórico es moderno (y consistente con la mayoría de las acuarelas de Xul del periodo): líneas de contorno visibles, geometrización y simplificación de las formas, superposición traslúcida de sus partes, colores planos...). En cambio, la figura antropomórfica ubicada en el sector europeo está construida a partir de técnicas diferentes, con menor peso visual en los contornos y exhibiendo pequeños volúmenes modelados con luces y sombras (fáciles de observar en el cuello, el busto y la nariz). Así, Xul la acerca sutilmente al realismo europeo, orientado a producir una ilusión de realidad mediante el ocultamiento de las líneas de dibujo y bordes de las figuras y la producción de efectos de volumen a través del color, entre otras convenciones. La elección enlaza la figura con la tradición pictórica europea dominante desde el Renacimiento y, por contraste, subraya el acto dislocatorio (cfr. Aguilar 2003) del lenguaje vanguardista utilizado en la construcción del sector de la imagen reservado a América. En cierta forma y generalizando podría decirse que en esta acuarela el lenguaje nuevo estaría reservado para América y el tradicional -pasado_, para Europa.

Xul parece enlazar la renovación artística con la necesidad de independencia cultural: para nuevos tiempos, nuevos lenguajes. Eso se manifiesta, por ejemplo, en los textos sobre Pettoruti que escribe en 1923 y 1924, uno de los cuales concluye con la sentencia: "Porque no terminaron aún para nuestra América las guerras de independencia. // En arte, uno de sus fuertes campeones es el pintor Emilio Pettoruti" (Xul Solar 2005: 111). El mismo mandato de reinventar las formas de expresión acompañando las transformaciones histórico-sociales aparece en Visión de Anáhuac como afirmación para el momento de la conquista y como experimentación para el contexto de enunciación. Al respecto, Perkowska Álvarez sostiene que en 1519 y en 1915, México se está transformando en un mundo nuevo y "para expresar este cambio, participar en él o describir el mundo nuevo deseado - el proceso que Reyes denomina en otro texto 'la búsqueda del alma nacional' — hay que recurrir a un arte nuevo" (2001: 86). De modo que Visión de Anáhuac (como la acuarela América) articula circunstancias 
históricas cambiantes con la búsqueda de formas de expresión artística que acompasen las transformaciones producidas en el marco de la Conquista y de la Revolución. En este sentido, vale destacar que 1915 no sólo tiene como referente la Revolución mexicana, sino también las vanguardias artísticas europeas y latinoamericanas, sustrato común a Reyes y a Xul.

Dado que los actos dislocatorios y la expansión de fronteras artísticas son rasgos característicos del vanguardismo (cfr. Aguilar 2003), nos interesa la circulación recíproca entre imagen y palabra, constitutiva de acuarelas de Xul a través del letrismo y estructurante del ensayo de Reyes. Jiménez de Báez, por ejemplo, describe el primer apartado de Visión de Anáhuac como una integración de la lengua escrita y el lenguaje visual, donde por un momento, como anuncia el título, la imagen deja de lado la palabra. Perkowska Álvarez identifica estrategias propias del cubismo, cuya presencia explica por una necesidad de Reyes de forjar un arte nuevo al calor del cambio social y a través de medios formales que subrayen su distanciamiento de "la ideología dominante y la retórica que lo encarnaba" (2001: 88). Destaca en el ensayo de Reyes dos procedimientos centrales del cubismo utilizados para expresar el carácter múltiple y complejo de la realidad mexicana pasada y presente: la fragmentación y la yuxtaposición. ${ }^{6}$ Precisamente se trata de dos operatorias constitutivas de la producción de Xul, junto con la aglutinación, la superposición y la simplificación. ${ }^{7}$

6 Perkowska identifica marcas de construcción cubista a través de la fragmentación y la yuxtaposición en numerosos elementos de la estructura de Visión de Anáhuac; algunas son la división en apartados casi autónomos que ofrecen diferentes vías de acceso al mismo objeto y articulan una visión múltiple y simultánea al presentarlo mediante géneros discursivos diversos (etnografía histórico-literaria, crónica, análisis literario, poesía y filosofía), el abandono del orden cronológico, la subdivisión de los apartados que intensifica la multiplicidad de perspectivas, la yuxtaposición de visiones desde afuera y desde adentro, así como desde distintos puntos temporales, la sumatoria de voces (Cortés, Díaz del Castillo, López de Gómara, Ramusio, entre otros) que interrumpen el discurso interpretativo. De esta manera, afirma, el texto se constituye como un cuadro cubista, donde una variedad de visiones articula un orden espacial simultáneo.

7 En forma breve, podemos señalar que en la producción de Xul entre 1922 y comienzos de los treinta las operatorias mencionadas operan como vasos comunicantes entre sus textos escritos y visuales, respondiendo a una estrategia general de montaje (cfr. Gil 2018). En sus imágenes prevalecen atmósferas inestables, de composición y 
La coincidencia es significativa en tanto da cuenta de una búsqueda simultánea de formas de expresión para interrogar el presente, que reemplacen al realismo y al positivismo cientificista. En los dos artistas, las operatorias mencionadas distancian los textos de la representación lineal y sucesiva, acercándolos a la simultaneidad de tiempos y visiones. Asimismo, Perkowska Álvarez afirma que el ensayo de Reyes crea un orden espacial simultáneo y que mediante el montaje crea una red o ensamblaje donde interactúan una multiplicidad de imágenes, conceptos, recursos, perspectivas, discursos, etc. Visión de Anáhuac no establece una diferencia entre el pasado prehispánico y el presente, sino que monta uno en otro, de modo equivalente a las superposiciones temporales de la acuarela América, donde el instante de la Conquista incluye el pasado precolombino, la Colonia y el presente. Los dos textos presentan un montaje de tiempos: la inminencia del contacto cultural, el pasado prehispánico, la Colonia y la transculturación. Los tiempos no aparecen como momentos secuenciados de una narración histórica, sino superpuestos por referencias a la Conquista, la Colonia, el presente de enunciación, la tradición pictórica europea y su puesta en crisis por las vanguardias, el mito y figuras prehispánicas como la flor o la serpiente, reapropiadas y actualizadas de continuo por Xul Solar y Reyes.

\footnotetext{
figuras fragmentadas, por ejemplo, en la acuarela América se observan secciones entrecortadas, casi flotantes, interrumpidas y superpuestas entre sí, que evocan en simultáneo tierra-mar-cielo. A su vez, en la expresión navesierpe se aprecia la aglutinación (así como en la imagen repetida en muchos textos visuales de embarcaciones-serpientes), procedimiento nodal en la morfología del neocriollo (cfr. Nelson 2012; Schwartz 2006). Lo mismo puede verse en Proa, desde un juego de superposición y yuxtaposición de signos plásticos y verbales que orienta el sentido de la imagen: sobre la proa-pintada del barco que tripulan los directores de la revista se superpone una PROA-escrita y entre los astros, un GENIO-escrito yuxtapuesto a un genio-pintado. Según la orientación de los mapas, el barco/Proa avanza desde América hacia Europa, pero en lugar del viejo continente, se ve un perfil de barco con la inscripción ELDORADO, invirtiendo el sentido de la ciudad mítica, objeto de deseo e inspiración de los conquistadores en América. Las yuxtaposiciones y superposiciones de imágenes y palabras construyen una evocación a la vanguardia artística lanzada a la conquista de Europa. Estas marcas reenvían por equivalencia a muchas acuarelas del período, como Nana Watzin, Por su cruz jura, Fluctúa navesierpe y otras. Armando y Fantoni (1997) destacan la superposición y la yuxtaposición en acuarelas vinculadas con códices prehispánicos (entre ellas, las mencionadas Tlaloc y Nana Watin) y Flores (2015) vincula Piai con el surrealismo a través de mecanismos de yuxtaposición y condensación.
} 
Desde esta convergencia de tiempos se trasluce una construcción temporal no lineal, sino convulsionada con el espesor de capas superpuestas y orientada a un movimiento circular que hace posibles los montajes. Mediante el montaje, tanto Xul como Reyes cuestionan la adjudicación de un sentido único para América, importado de Europa, y provocan como efecto que el pasado americano y el presente se perciban interactuando; es decir, no como momentos diferenciados y acabados, sino como parte de un tejido "múltiple y heterogéneo" (Pacheco: 15) por descifrar. Esta estrategia compositiva supone la convivencia de elementos heterogéneos que no se sintetizan entre sí, sino que conforman unidades múltiples. Por ello, su uso en el solapamiento del pasado prehispánico y el presente en Visión de Anáhuac y en las acuarelas de Xul reenvía, en cierta forma, al carácter múltiple y conflictivo de la cultura latinoamericana. Asimismo, contienen una transculturación nodal de la región: la que se produce entre oralidad y escritura. ${ }^{8}$

Jorge Monteleone afirma que el núcleo estilístico de la prosa de Reyes radica en una intención de "provocar un residuo de oralidad y un efecto de conversación" (7), rasgo palpable en su descripción de Anáhuac, donde, por ejemplo: "el zumbar y el ruido de la plaza — dice Bernal Díaz- asombra a los mismos que han estado en Constantinopla y en Roma" (Reyes 2006: 41). En la matriz común entre el ensayo de Reyes y los textos visuales de Xul encontramos una tensión entre sistemas dominantes importados de Europa como la escritura (tradición letrada) y las bellas artes, medios privilegiados por ambos, y elementos perimidos de la tradición popular. Nos referimos a marcas y efectos de oralidad ${ }^{9}$ y a la recuperación de archivos latinoamericanos precolombinos y coloniales, como los códices mesoamericanos de inicios de la Colonia (tal vez, primeros textos transcultu-

8 En palabras de Pacheco: "uno de los parámetros que con mayor evidencia manifiesta el carácter múltiple y heterogéneo de esa nueva realidad es la continua tensión que ha existido a lo largo de su proceso histórico entre las manifestaciones canónicas o consagradas de las sucesivas culturas dominantes y aquellas otras modalidades de producción cultural de origen popular" (15).

9 Nana Watzin, por ejemplo, restituye la secuencialidad temporal de la narración oral mexica en la simultaneidad de la imagen pictórica, a la vez que traslada formas de la pronunciación a la palabra escrita (cfr. Gil 2018) y se organiza desde principios rítmico-sonoros (cfr. Cristiá 2011). 
rados del continente, donde la escritura castellana intenta asir la oralidad), cartas, crónicas e imágenes, que expresan el desafío que América supuso a la imaginación y el conocimiento de los europeos.

El análisis realizado hasta aquí nos permitiría identificar tres líneas rectoras de la matriz común a Visión de Anáhuac y a las acuarelas de Xul Solar: la construcción de un diálogo entre el pasado prehispánico imaginado y el presente de la enunciación hacia una proyección del futuro deseado; estrategias de montaje materializadas en operaciones de fragmentación y yuxtaposición, y una circulación recíproca entre imagen y palabra, que incluye la provocación de efectos de oralidad en la visualidad. Es posible especular que mediante los montajes y superposiciones que otorgan a sus textos una matriz común, se manifiesta un programa o proyecto equivalente ante el deseo vanguardista de construir formas de expresión y lenguajes artísticos nuevos, necesarios para la conquista de independencia y autonomía culturales.

Reyes es una de las figuras más destacadas en los debates sobre cómo alcanzar un arte genuinamente nacional o americano, con un posicionamiento expresado en su famosa sentencia: "la única manera de ser provechosamente nacional consiste en ser generosamente universal, pues nunca la parte se entendió sin el todo" (1996: 439). Visión de Anáhuac, como las acuarelas de Xul Solar y sus textos sobre Pettoruti, materializan en formas artísticas esta perspectiva. Operan como ensayos de la transformación de las formas de expresión, interrogando la naturaleza de la parte y su actualización en el todo. Pensamos que esta perspectiva se ve atravesada de diversos modos por los "viajes intelectuales" (Colombi 2004) de Reyes y de Xul. En este sentido, coincidimos con Montgomery (2017), quien considera que el "anticolonialismo" de muchos de los artistas y críticos latinoamericanos de los años veinte y treinta absorbe un discurso en circulación en Europa durante sus viajes, frente al cual reconocen y problematizan el potencial político de utilizar y resignificar las herramientas conceptuales hegemónicas.

Es pertinente recordar el estudio de Beatriz Colombi sobre viajeros intelectuales latinoamericanos entre 1880 y 1915 (trabajo que dedica un capítulo a Reyes), donde afirma: 
El desplazamiento coloca a prueba la autofiguración del sujeto así como su pertenencia a una cultura periférica, por eso la escritura desterritorializada fue vector de numerosas metáforas culturales (nuestra América, latinoamericanismo, hispanoamericanismo, iberoamericanismo) formuladas como narraciones de autoafirmación, emancipación o descolonización cultural (Colombi 2004: 15).

Para Colombi, la experiencia del "escritor desprendido de su medio" (14) supone una producción de textos signados por una práctica de desplazamientos entre destinos, lenguas y contextos. Las trayectorias personales de Xul Solar y de Alfonso Reyes incluyen largas estadías en Europa que imprimen marcas en sus producciones, en una búsqueda de diferenciación del discurso propio y de autoafirmación de una identidad diferente. ${ }^{10}$ La asociación entre la autofiguración del viajero y el uso de metáforas que afirmarían una pertenencia cultural distinta de la europea (periférica en términos de Colombi), permea en textos de Xul y de Reyes hacia una modulación identitaria — ya latinoamericana, ya nacional— que demanda encontrar modos de independizarse culturalmente de Europa, sin rechazar sus aportes.

En textos de ambos, por ejemplo, encontramos un imperativo de diferenciación cultural de Europa a través de una apelación al principio iluminista desarrollado por Kant sobre la mayoría de edad como ejercicio pleno de la razón y de la condición del hombre de pensar por sí mismo y regir su propia vida (cfr. Kant 2013). En uno de los artículos programáticos sobre Pettoruti [1923-1924], en los que Xul Solar posiciona la emergencia de una vanguardia artística neocriolla como un paso necesario hacia la independencia cultural latinoamericana, afirma:

10 Xul viaja a Europa en 1912, Reyes en 1913 y ambos regresan en 1924. Por razones diversas, pero igualmente vinculadas con la guerra, sus experiencias europeas no se concentran en París, meca simbólica de los artistas latinoamericanos de comienzos del siglo Xx, sino en ciudades italianas en el caso de Xul y españolas en el de Reyes. Los dos consolidan allí vínculos intelectuales y creativos que serán nodales en sus trayectorias posteriores, como la amistad de Solar con el pintor Emilio Pettoruti y la de Reyes con Pedro Henríquez Ureña. No es menor señalar que entre 1927 y 1930 y 1936-1937, mientras Reyes es embajador en Argentina, ambos intervienen activamente en el campo cultural porteño y comparten ámbitos, vínculos y posicionamientos (Reyes 2015; Abós 2004; Artundo 2005). 
Somos y nos sentimos nuevos, a nuestra meta nueva no conducen caminos viejos y ajenos. Diferenciémonos. Somos mayores de edad y aún no hemos terminado las guerras pro independencia. Acabe ya la tutela moral de Europa. Asimilemos sí, lo digerible, amemos a nuestros maestros; pero no queramos más nuestras únicas Mecas en ultra mar (Xul Solar 2005: 99).

En "Notas sobre la inteligencia americana"11 [1936] Reyes señala:

Hace tiempo que entre España y nosotros existe un sentimiento de nivelación e igualdad. Y ahora yo digo ante el tribunal de pensadores internacionales que me escucha: reconocemos el derecho a la ciudadanía universal que ya hemos conquistado. Hemos alcanzado la mayoría de edad. Muy pronto os habituaréis a contar con nosotros (1997: 90).

Los fragmentos citados de Xul y de Reyes apelan a la mayoría de edad en un sentido equivalente: una afirmación de nuestra independencia; es decir, del sujeto colectivo latinoamericano del que formarían parte enunciador y lectores. A su vez, se desarrollan desde un mismo imperativo convocante: "diferenciémonos" (Xul Solar 2005: 99), no como adolescentes que construyen su mundo desde la oposición con el heredado, sino como adultos. Según el principio kantiano, la mayoría de edad implica una decisión de dejar de vivir bajo conducción ajena y valerse del entendimiento propio, por ello la apelación a esta condición en los textos apunta al carácter volitivo de la diferenciación de Europa. Como quien reclama a alguien que se haga cargo de sí mismo, el texto de Xul insta a terminar "las guerras pro independencia" (99) y a tomar la decisión de concluir en el plano cultural, la tarea iniciada un siglo atrás en el terreno político. Mientras que el de Reyes, doce años posterior, coloca la mayoría de edad como un estado alcanzado por las naciones americanas en forma de conquista, no de concesión, y demanda su reconocimiento internacional.

En el texto de Reyes, la apelación a la mayoría de edad se vincula con otra metáfora de peso en los debates intelectuales de los veinte y treinta: el reconocimiento del derecho a la ciudadanía universal. Lo que aquí se ve

11 El texto es resultado de una conferencia dictada por Alfonso Reyes en Buenos Aires en 1936, en el marco del XIV Congreso Internacional de los PEN Clubs y la VII Conversación de la Organización de Cooperación Intelectual (Colombi 2011). 
como exhortación discursiva, se observa en la construcción formal de Visión de Anáhuac y de las acuarelas de Xul seleccionadas, mediante la utilización de archivos culturales europeos y latinoamericanos, ya dominantes ya perimidos, y su resignificación al refractarlos en imágenes de autoafirmación y emancipación cultural. Respecto de Reyes, y creemos que vale también para Xul, Colombi afirma que "el viaje y su cultura le confirieron las credenciales para esa ciudadanía" (2004: 145). Desde esta perspectiva, los dos - como otros viajeros del mismo período- se autoimponen la tarea de actuar como agentes modernizadores (cfr. Colombi 2004) de sus países de origen, al principio desde Europa y, luego, en América.

La tarea modernizadora en Xul Solar y en Reyes aspira a una descolonización cultural que no desconoce (ni desaprovecha) la tradición europea y que se autoafirma en la actualización del pasado americano. En este sentido, es importante recordar que el proceso cultural que Ángel Rama conceptualiza como transculturación alberga un trabajo simultáneo sobre fuentes europeas y americanas asociadas en un "pensar mítico" (64), del que surgen fenómenos originales e independientes. Rama afirma que en las primeras décadas del siglo xx, los mitos prehispánicos constituyen en Europa un novedoso objeto internacionalizado que regresa a nuestro continente a través de latinoamericanos viajeros. A diferencia de las apropiaciones de artistas europeos, los americanos restituirían elementos de una cosmovisión que pone en entredicho el discurso lógico-racional occidental. De algún modo intentamos observarlo en la lectura relacional de Visión de Anáhuac y ciertas acuarelas de Xul, donde además de la evidente utilización y superposición de fuentes documentales prehispánicas y coloniales, identificamos una recuperación simbólica de la temporalidad simultánea y circular propia de cosmovisiones americanas y fundante de sus mitos.

Según desarrollamos, mediante el montaje de segmentos heterogéneos, fragmentados y yuxtapuestos (sean lenguajes, archivos, discursos, visiones, tiempos, etc.) Reyes y Xul despliegan una "pintura de civilizaciones" (Reyes 2006: 27) prehispánicas cargadas de presente, de modo que ambos tiempos se traman en una construcción simultánea. Ello moviliza un sentido utópico que amplía el campo de lo posible (cfr. Ricoeur 2009), en tanto la imaginación del pasado moldea el deseo de un futuro distinto. 
Como afirma Perkowska Álvarez en su trabajo sobre Reyes: "al transformar el modo de mirar hacia el pasado se formula una nueva manera de actuar en el futuro" (96). Esta operación reinserta el tiempo mitológico en el presente moderno de la vanguardia y en la proyección utópica futura, e imprime en los textos un sesgo mítico a partir de un montaje de tiempos que desarticula la secuencia lineal de pasado, presente y futuro. En consecuencia, se anula también la organización de narraciones vinculadas con nociones de progreso, evolución y desarrollo, abriendo la posibilidad utópica de que se produzca un salto fuera del continuum, una transformación deseada e inesperada.

\section{Bibliografía}

Abós, Álvaro. Xul Solar. Pintor del misterio. Buenos Aires: Sudamericana, 2004.

Aguilar, Gonzalo. Poesía concreta brasileña: las vanguardias en la encrucijada modernista. Rosario: Beatriz Viterbo, 2003.

Armando, Adriana B. y Guillermo A. Fantoni. "Recorridos americanos: algunos temas en Xul Solar", en IV Jornadas de Teoría e Historia del arte: el arte entre lo público y lo privado. Buenos Aires: Centro Argentino de Investigadores de Arte, 1995. 297-315.

Armando, Adriana B. y Guillermo A. Fantoni. “Dioses y códices prehispánicos en la obra de Xul Solar", en Ciencia Hoy 37 (1997). Artículo en línea disponible en: <http://cienciahoy.org.ar/1997/01/dioses-y-codices-prehispanicos-en-la-obrade-xul-solar/> [consultado el 13 de marzo de 2019].

Artundo, Patricia. "A. Xul Solar: una imagen pública posible", en Alejandro Xul Solar. Entrevistas, artículos y textos inéditos. Buenos Aires: Corregidor, 2005. 7-54.

ARtundo, PATRICIA. "El encuentro entre el mago y el pintor: Aleister Crowley y Alejandro Xul Solar", en Xul Solar Panactivista. Curaduría de Cecilia Rabossi. Buenos Aires: Museo Nacional de Bellas Artes, 2017. 65-74.

Barthes, Roland. La aventura semiológica. Trad. Ramón Alcalde. Barcelona: Paidós, 1990.

BARTHES, Roland. El grado cero de la escritura y Nuevos ensayos críticos. Trad. Nicolás Rosa. México: Siglo XXI, 2011.

BORGES, JORGE LUIS. "La muralla y los libros", en Otras inquisiciones [1952], en Obras completas 6, Buenos Aires: Sudamericana, 2011. 9-12.

Colombi, BeAtriz. Viaje intelectual. Migraciones y desplazamientos en América Latina (1880-1915). Rosario: Beatriz Viterbo, 2004.

Colombi, BeAtriz. "Alfonso Reyes y las 'Notas sobre la inteligencia americana': una lectura en red", en Cuadernos del CILHA, 14 (2011): 109-123.

Cristí́, Cintia. Xul Solar, un músico visual. La música en su vida y obra. 2a. ed. Buenos Aires: Gourmet Musical, 2011. 
Fischler, Graciela Viviana. Xul Solar. 2 años y 229 libros. Trabajo final integrador para la Licenciatura en Artes. Buenos Aires: Universidad de Palermo. 2009. Inédito.

Flores, EnRIQue. Gauchillaje entre demonios. Una cosmovisión correntina. Del Gauchito Gil a Francisco Madariaga. México: Universidad Nacional Autónoma de México, 2015.

GIL, SABRINA. "Imágenes narrativas, palabras visuales y unidad latinoamericana en Xul Solar", en Mónica Marinone y Gabriela Tineo (coords.). Latinoamérica entre lenguajes y lenguas. Mar del Plata, Argentina: Editorial de la Universidad Nacional de Mar del Plata, 2018. 77-113.

JimÉNEZ DE BÁEZ, IVETTE. "El discurso omitido en Visión de Anáhuac", en Nueva Revista de Filología Hispánica, XXXVII-2 (1989): 465-479.

Kant, Emmanuel. Filosofía de la historia. Trad. Eugenio Ímaz. México: Fondo de Cultura Económica, 2013.

Monteleone, Jorge. "Alfonso Reyes, el conversador", en Boletín del Centro de Estudios de Teoría y Crítica Literaria. Rosario, Argentina, 11 (diciembre, 2003): $1-11$.

MOntgomery, Harper. The Mobility of Modernism. Art and Criticism in 1920s Latin America. Austin: University of Texas Press, 2017.

Nelson, Daniel. "Un texto proteico: los San Signos de Xul Solar", en Los San Signos: Xul Solar y el I Ching. Buenos Aires: El Hilo de Ariadna, 2012. 21-102.

PACHeCO, CARlos. La comarca oral. La ficcionalización de la oralidad cultural en la narrativa latinoamericana contemporánea. Caracas: La Casa de Bello, 1992.

Perkowska Álvarez, Magdalena. "La forma y el compromiso en Visión de Anáhuac de Alfonso Reyes", en Nueva Revista de Filología Hispánica, XLIX-1 (2001): 81-96.

RAMA, ÁNGEL. Transculturación narrativa en América Latina. Buenos Aires: El Andariego, 2008.

Reyes, Alfonso. "A vuelta de correo" [1932], en Obras completas, t. VII. México: Fondo de Cultura Económica, 1996. 427-449.

Reyes, Alfonso. "Notas sobre la inteligencia americana" [1936], en Obras completas, t. IX. México: Fondo de Cultura Económica, 1997. 82-90.

Reyes, Alfonso. "Visión de Anáhuac (1519)" [1915], en Visión de Anáhuac (1519), Ifigenia cruel. México: Universidad Nacional Autónoma de México, 2006. $27-$ 62 (colección Voz viva de México).

Reyes, Alicia. Genio y figura de Alfonso Reyes [1 era ed. digital]. México: Fondo de Cultura Económica, 2015.

Ricoeur, Paul. Ideología y utopía. Trad. Alberto Luis Bixio. Barcelona: Gedisa, 2009.

Rovira Collado, José. "La Visión de Anáhuac: Reyes recupera a Ramusio", en América sin Nombre. Boletín de la Unidad de Investigación de la Universidad de Alicante, 5-6 (2004): 202-207.

SChWARTZ, JORGE. "Una especie de territorio mental sudamericano prebabélico", en Ramona. Revista de Artes Visuales. Buenos Aires, 61 (junio, 2006): 32-43.

Xul Solar, Alejandro. Entrevistas, artículos y textos inéditos. Ed. Patricia M. Artundo. Buenos Aires: Corregidor, 2005. 
Créditos de las imágenes

Todas las imágenes de Xul Solar se reproducen con el consentimiento de la Fundación Pan Klub-Museo Xul Solar, Buenos Aires, Argentina. D. R. Fundación Pan Klub-Museo Xul Solar.

1. Xul Solar, Proa, 1925, 50 x 33, acuarela y gouache, Museo Nacional de Bellas Artes, Argentina.

2. Xul Solar, Ña Diáfana, 1923, 26 x 32, acuarela y gouache, Fundación Pan KlubMuseo Xul Solar, Argentina.

3. Xul Solar, Serpientes y cintas, 1925, 28 x 37,5, acuarela y pintura de plata, colección particular.

4. Xul Solar, Tlaloc, 1913, 26 × 32, acuarela y gouache, localización desconocida.

5. Xul Solar, Mundo, 1925, 25,5 x 32,5, acuarela y gouache, Halle, Estados Unidos.

6. Xul Solar, Bau, 1926, 16 × 21, acuarela y tinta, localización desconocida.

7. Xul Solar, Danza, 1925, 24,8 x 31, acuarela y gouache, colección particular.

8. Xul Solar, América, 1923, 09,5 x 23, acuarela, gouache y tinta, Rubbers, Argentina.

SABRINA GIL

Es investigadora y docente de la Universidad Nacional de Mar del Plata, Argentina. Se especializa en la investigación de textos artísticos latinoamericanos de los siglos xx y XXI, con atención a procesos de circulación de palabra e imagen en la producción de discursos orientados a la reflexión sobre Latinoamérica contemporánea. Sobre ello ha publicado en revistas especializadas y volúmenes colectivos, el más reciente: Latinoamérica entre lenguajes y lenguas (2018), coordinado por Mónica Marinone y Gabriela Tineo. Es doctora en Letras por la UNMDP, profesora y licenciada en Historia por la misma universidad, Especialista en Lenguajes Artísticos por la Universidad Nacional de La Plata y profesora de Juegos Dramáticos por la Universidad Nacional del Centro de la Provincia de Buenos Aires. Es becaria posdoctoral del CONICET con lugar de trabajo en el grupo de investigación "Literatura y cultura latinoamericanas" del CELEHIS-UNMDP. 